\title{
Increase in energy efficiency of tunnel composting by bio leaching and biogas production
}

\author{
N. Bauerschlag ${ }^{1}$ and Th. Pretz ${ }^{1}$ \\ ${ }^{1}$ Department of Processing and Recycling I.A.R. \\ RWTH Aachen University \\ Wuellnerstr. 2 - 52062 Aachen (Germany) \\ Phone number:+ 49241 8095711, e-mail: Bauerschlag@ifa.rwth-aachen.de
}

\begin{abstract}
.
Bio waste treatment can be done by composting or by digestion. Both ways of treatment have their advantages and disadvantages. The increase in energy efficiency of tunnel composting approached by a bio leaching system and bio gas production is one part of the EnBV research project.

The reduction of organic matter by bio leaching and the enrichment of carbons in the leachate water can be used for increasing the energy efficiency.
\end{abstract}

\section{Key words}

Bio waste, composting, bio leaching, biogas, energy efficiency.

\section{Introduction}

Over 127 Mio. $t$ per year of bio waste is produced in the EU27 and only $20 \%$ of this potential is used. Most of the bio waste is still going to landfill. About 80 Mio. $t$ of bio waste in the EU27 is uncontrolled biodegraded in landfills forming green house gases such as methane.

Uncontrolled green house gas emission can be reduced by using this potential of composting to produce dry solid fertilizer. Also the compost can be used as a substitution or replacement for humus soil, especially in the southern parts of Europe [1].

\section{Situation in Germany}

Over 8 million tons per year of bio waste were collected in Germany over the last decade. The collected bio waste from households is mostly treated in compost plants. Germany has about 800 compost plants compared to ca. 80 digestion plants, which are used for biogas production from bio waste [2].

About $80 \%$ of the German households have access to the separate bio waste collection system [3].

\section{Bio waste}

Bio waste itself is a very complex type of waste. It can be divided into two main types of waste:

- Kitchen waste

- Garden waste

Curb-side collection of bio waste consists of both types of waste kitchen and bio waste. Garden waste is mostly collected in a bring-in sites system.

Kitchen waste has a high content of food waste and therefore a high water content. Garden waste mostly consists of greenery or wooden waste. The total mass of bio waste and the ratio between kitchen and garden waste fluctuates considerably over the year. There are periods with proportionally more garden waste being produced such as in spring or autumn times. During the summer and winter the bio waste composition is dominated by kitchen waste. Fig. 1 shows the incoming of garden and bio waste relating to the average monthly input. In October ca. $70 \%$ more garden waste is collected compared to the average. In contrary in February the garden waste collected is $60 \%$ less than the average.

Due to fact that bio waste consists of both types of waste (kitchen and garden waste) the average monthly input fluctuates also considerably over the year.

Without garden waste the bio waste would have a more constant amount because it is dominated by kitchen waste. The amount of kitchen waste is constant over the year because it is not affected by vegetation periods. This has an effect on the treatment of the bio waste. 


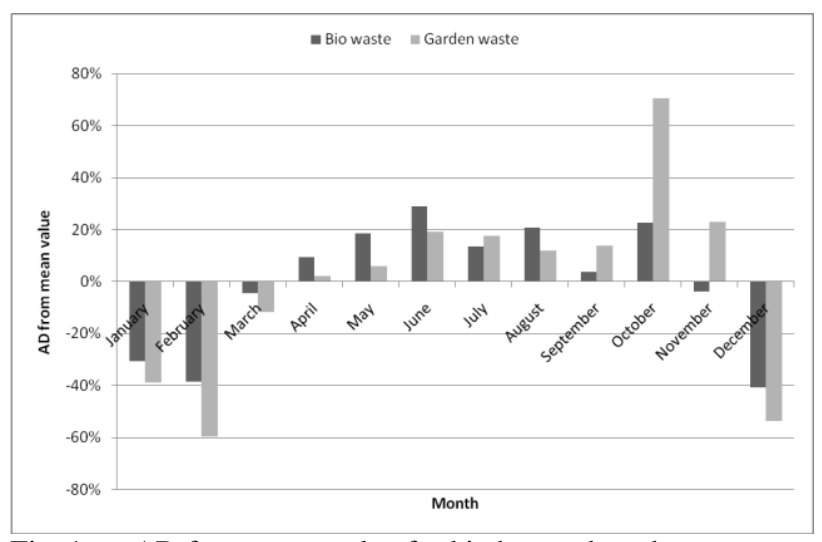

Fig. $1 \quad \mathrm{AD}$ from mean value for kitchen and garden waste

There is also a difference between kitchen and garden waste concerning their composition of carbon. While kitchen waste mostly consists of sugars that are easily degradable, garden waste incorporates a larger amount of lignine that is not as easy to degrade in aerobic conditions, even less in anaerobic conditions.

These differences in the amount of easy degradable carbons and the ratio between easy degradable and non easy degradable also needs to be taken into account in the matter of which treatment is more suitable for the waste.

Digestion processes are very sensitive to the input. The microorganisms need to be fed constantly with easy degradable carbons for a constant bio gas production. Non easy degradable carbons like lignine can be degraded within a digestion process but this takes a longer time within the fermenter and the bio gas production potential is not so high. As mentioned above the input fluctuates over the year which also means that the bio gas production is not constant over the year. Non easy degradable carbons can be degraded in a good and sustainable way by composting.

\section{Bio waste treatment}

Bio waste can be treated by composting or by digestion processes.

Composting is an aerobic process in which microorganisms convert the bio waste into compost, which can be used as fertilizer. In industrial composting plants the living conditions for the microorganisms can be optimized through procedural steps during the composting. This affects the time that is needed for the composting process.

One of the most important procedural steps is the aeration of bio waste over the whole duration of the composting process. The aeration is needed to allocate the required oxygen. It also regulates the temperature and moisture in the compost heap.

Over all the energy consumption for the composting is very high. Most of the energy is used for the aeration system. The energy demand of a composting plant cannot be substituted by biogas as is often done in digestion plants. Due to that fact classic composting has a negative energy balance.
Digestion plants are often chosen for treating bio waste because of the energy production from biogas. But what has to be taken into account is that a digestion process is very sensitive in matters of input material. Digestion plants need to be fed with a constant type of input material. This stability in the input material is not given by bio waste as mentioned before (chapter 3 ). Beside biogas, another main output stream of digestion plants are the solid fermentation residues. This has to be composted in order to fulfil the German law on bio waste treatment. Bio waste has to be sanitized, which is mostly done in a composting process which also can have an aeration system.

\section{Field of research}

Within our research we are working on the optimization of industrial composting processes to increase the energy efficiency.

The joint research project "Energieeffiziente Bioabfallverwertung (EnBV)" (FKZ 0327846 A\&B) is funded by the Federal Ministry of Economics and Technology of Germany.

The biggest potential to save energy in an industrial composting plant is to reduce the aeration. The reduction of the aeration can be achieved by reducing the value of organic material before the composting.

One approach to reduce the value of organic material within the EnBV research project is by bio leaching before composting.

The bio waste will be put into a composting tunnel. After the first day the bio waste material starts to heat up. That is the time when the bio leaching starts.

The bio leaching is using main parts of the overhead irrigation and draining system which is obligatory in a tunnel composting system. The water is sprinkled over the bio waste and percolates through it. The leachate water is captured underneath the compost tunnel.

While the water is percolating through the bio waste the process velocity of hydrolyses and acidification (known from the digestion process) will increase. The easy degradable carbons, e. g. sugars, will be degraded and the degradation products will be enriched in the water which affects the COD of the water.

Beside the processes of the hydrolyses and the acidification, the COD of the percolated water will increase because of elutriation effects.

The value of carbons in the compost tunnel will be reduced by bio leaching processes. After the bio leaching less organic material is in the composting tunnel and due to this fact less aeration is needed. The aeration can be reduced because less oxygen is needed for the aerobic metabolic rates of the microorganisms. Lower metabolic rates also means that the temperature will not increase that much and reduces the amount of discharged heat 
from the compost heap. The aeration for temperature control can be reduced.

After the bio leaching the percolated water have a high COD-level and a dry matter content of about $8 \%$. It can be fed into a digestion plant to produce biogas.

The biogas can be used to produce electric power through a CHP which could be used for the energy for aeration. Over all the demand of electricity for the composting process can be reduced and substituted by own produced electricity.

Bio leaching is a process that is already used for bio waste treatment. Those systems are aiming for a high bio gas production. The difference between the usual bio leaching process and the EnBV research project is that the research project is not aiming for a high biogas production.

Bio leaching systems which are trying to get a high bio gas production are using high water quantities. Such high water quantities can reduce the aeration characteristics of the compost heap. This can affect the quality of the produced compost.

High water quantities have impacts on the ventilation characteristic of the compost heap. The compost heap can be compressed by high water quantities and due to that fact the ventilation characteristic can be degraded. Water and elutriated material can block the pores. What in the end can cause a higher energy demand for the aeration than without bio leaching so that the increase in energy efficiency is failed.

\section{Conclusion}

The approach of reducing the energy consumption for aeration in the composting process by bio leaching will be tested within the EnBV research project.

The tests are done on an industrial scale on in a bio waste composting plant. The test will show the effects of the vegetation periods.

By using the bio leaching step before composting the potential for biogas production from the easy degradable carbons, which mostly come from kitchen waste, can be used. This bio gas potential is not used in a normal composting plant.

The easy degradable carbons which mostly come from the kitchen waste can be enriched in the leachate water. As mentioned above the amount of kitchen waste is more constant than the amount of bio waste itself due to the fact that bio waste also consists of kitchen and garden waste.

The enrichment of carbon into the leachate water can come mostly from the easy degradable carbons from kitchen waste. Due to that fact the quality of the leachate water which is used for biogas production can be more constant over the year for example in the matter of ratio between carbon and nitrogen.
The bio gas production rate from a constant input stream is higher due to the fact that the microorganisms are used to the input material.

Bio leaching systems for bio waste treatment are already on market. What is different to the EnBV approach is that the standard bio leaching systems are used for bio gas production. That means that all specifications are made for a high bio gas recovery from the bio waste. Within the EnBV process the main target is to reduce the energy consumption of a tunnel composting process by retaining the quality standard of the compost. The compost quality must be the same with or without the bio leaching system.

The produced compost can be used as a substitution or replacement for humus soil. It has high quality standards.

The EnBV research project is trying to combine the advantages from composting and digestion by taking into account that kitchen and garden waste are so different. Kitchen waste can be used for digestion processes and garden waste is better degradable within a compost system.

\section{References}

[1] Verband der Humus- und Erdenwirtschaft e.V. (editor), "Bioabfälle und Kompostierung - ein Blick über die Grenzen”, in HuMuss Nr. 21 (2009), p. 4.

[2] T. Turk, et al., "Effektive Energiegewinnung aus Abfällen", in Müllmagazin 4. Quartal (19. Jhg.), 15. Januar 2007, Nr. 4/2006, pp. $49-53$

[3] D. Henssen, "Einführung und Optimierung der getrennt Sammlung zur Nutzbarmachung von Bioabfall", Mai 2009 (1. Auflage)

\section{Contact Details}

Dipl.-Ing. Nils Bauerschlag

Department of Processing and Recycling I.A.R. RWTH Aachen University

Wuellnerstr. 2

52062 Aachen

Germany

Phone: 00492418095711

Fax: 00492418092232

Email: bauerschlag@ifa.rwth-aachen.de

Web: www.iar.rwth-aachen.de 